\title{
Health beliefs about lifestyle habits differ between patients and spouses 1 year after a cardiac event - a qualitative analysis based on the Health Belief Model
}

Anita Kärner Köhler, Staffan Nilsson, Tiny J aarsma and Pia Tingström

The self-archived postprint version of this journal article is available at Linköping University Institutional Repository (DiVA):

http:/ / urn.kb.se/ resolve?urn=urn:nbn:se:liu:diva-130771

N.B.: When citing this work, cite the original publication.

Kärner Köhler, A., Nilsson, S., J aarsma, T., Tingström, P., (2017), Health beliefs about lifestyle habits differ between patients and spouses 1 year after a cardiac event - a qualitative analysis based on the Health Belief Model, Scandinavian J ournal of Caring Sciences, 31(2), 332-341.

https:// doi.org/ 10.1111/ scs.12351

Original publication available at:

https:// doi.org/ 10.1111/scs.12351

Copyright: Wiley (12 months)

http:/ / eu.wiley.com/WileyCDA/ 


\section{Health beliefs about lifestyle habits differ between patients and spouses one year after a cardiac event- a qualitative analysis based on the Health Belief Model}

Anita Kärner Köhler ${ }^{1}$, Staffan Nilsson ${ }^{2,3}$, Tiny Jaarsma ${ }^{1}$ and Pia Tingström ${ }^{2}$ INSTITUTIONAL ADDRESSES

1) Department of Social and Welfare studies (HAV), Linkoping University, Sweden

2) Department of Medical and Health Sciences (IMH), Linkoping University, Sweden

3) Vikbolandet Health Care Center, Primary Health Care in eastern Ostergotland, Region

Ostergotland, Norrkoping, Sweden

E-MAIL ADDRESSES OF AUTHORS

Correspondence to A. Kärner Köhler. E-mail: anita.karner@liu.se

staffan.g.nilsson@liu.se; tiny.jaarsma@liu.se ; pia.tingstrom@liu.se

Anita Kärner Köhler, PhD MPH RN, University lecturer, Department of Social and Welfare studies (HAV), Linkoping University, Sweden. Division Health Activity Care, Department of Social and Welfare Studies, SE-601 74 Norrkoping, Sweden. Mobile Phone: +46 (0)11-36 3506 Visiting address: Kungsgatan 40, Norrkoping

Staffan Nilsson, PhD GP, University lecturer, Department of Medical and Health Sciences (IMH), Linkoping University, Sweden. Vikbolandet Health Care Centre, Primary Health Care in eastern Ostergotland, Region Ostergotland, Norrkoping, Sweden

Tiny Jaarsma, PhD RN, Professor, Department of Social and Welfare studies (HAV), Linkoping University, Sweden

Pia Tingström, PhD RN, Department of Medical and Health Sciences (IMH), Linkoping University, Sweden

\section{ACKNOWLEDGEMENTS}

The authors thank all the patients and spouses who took part in this study. We would also like to thank all the registered nurses who facilitated access to all the patients who participated, and Johannes Arnell for making this study possible. We are also grateful to Joakim Engstrand for his assistance in transcribing the recorded focus group interviews.

\section{Please, continue to next page.}




\section{AUTHOR CONTRIBUTIONS}

All authors have agreed on the final version of the paper, and have made substantial contributions to more than one of the following criteria: conception and design, acquisition of data, or analysis and interpretation of data; drafting the article or revising it critically for important intellectual content, as recommended by the IC- MJE http://www.icmje.org/

\section{ETHICAL APPROVAL}

The study complies with the Declaration of Helsinki and was approved by The Regional Ethical Review Board in Linkoping, regarding the patients: Dnr 2010/128-31 and the spouses: 2013/55-32. All participants gave written informed consent.

\section{FUNDING}

This study is funded by the Swedish Heart and Lung Association, project number E103/13; E090/14 and Region Ostergotland, Sweden, project number LIO-433801. 


\section{Abstract}

Background: Spousal concordance on risk factors and lifestyle habits exists, and can partly be explained by patients' and spouses' health beliefs, and underuse of cardiac rehabilitation. However, there have been very few qualitative comparisons of health beliefs between patients and spouses after a cardiac event.

Aim: To examine and qualitatively compare the health beliefs of patients with coronary heart disease and their spouses about lifestyle habits, one year after the cardiac event.

Design: Explorative and descriptive

Method: Semi-structured focus group interviews were conducted with patients $(n=14)$ one year after a cardiac event, as well as individual interviews with spouses $(n=8)$. The transcriptions underwent a deductive qualitative content analysis, within the framework of the Health Belief Model.

Findings: Patients' and spouses' health beliefs about lifestyle habits qualitatively differed in most predetermined main analytical categories of the Health Belief Model. The patients relied more on their own capacity and the health care system than on collaboration with their spouses who instead emphasised the importance of mutual activities to establish lifestyle habits. The spouses therefore experienced problems with different family preferences compared to the patients' wishes. Moreover, only patients believed supervised exercise was beneficial for risk reduction of coronary heart disease and they related barriers for medication to a self-healing body and a meaningless life without relatives and old habits. Patients and spouses agreed that despite the severity of illness, life was captured, and that normalisation to a life as usual was possible.

Conclusion: The patients' and spouses' qualitatively different health beliefs regarding healthrelated behaviours implies a new approach. Nurses and associated professionals need to follow-up patients' and spouses' in primary health care to support them in a tailored way e.g. in problem-based sessions. Recognition and understanding of their different views and otherness could lead to compromises and goals to work with. 


\section{Background}

The importance of couple-oriented interventions in cardiac rehabilitation (CR) after an event of coronary heart disease (CHD) has been well described [1-5]. There is a significant positive concordance between patients and spouses for the majority of coronary risk factors [6] e.g. for smoking, physical inactivity, hypercholesterolemia and diabetes mellitus [5].

Despite the general concordance on coronary risk factors, data from the EUROASPIRE III survey showed that of patients with CHD followed-up after 1.4 years, 38\% lived with obesity (in Sweden more than 45\%); 16\% smoked (of those smoking before hospitalisation 51\% still smoked); and almost $40 \%$ had hypertension[7]. These high figures might partly be explained by the current underuse of CR [8]. About half of the patients received advice to attend CR [9] and only $36 \%$ of all patients with CHD benefitted from CR in Europe [8]. Thus, a reasonable assumption is that even fewer spouses than patients do not take advantage of CR for their own health and/or in order to support the patient.

Although the knowledge that spousal concordance regarding coronary risk factors and lifestyle habits exists, there is little information on spouses' support to the patient in daily life. We previously described five different roles of spousal support after a cardiac event. These roles were described as being participative, meaning that the spouse took a practical part in the lifestyle change; regulative, i.e. the spouse tried to influence the patient to change lifestyle habits; observational, i.e. the spouse was passive and compliant towards the patient's lifestyle change; incapacitated, which denoted an inability to be supportive, and dissociative, which entailed a reluctance to become involved in changes of lifestyle habits of the patient. No spouse took on the same supportive role in all situations. Instead, the spouse's supportive roles depended on the current situation [10]. Reasons that spouses support the patient in different ways may be that spouses have diverse experiences of control over the partner's heart condition, and they lack understanding of the information they are given[11, 12]. Illness beliefs have been identified as an important determinant of patients' changes in lifestyle after a cardiac event [13]. Three key themes based on patients' reports were identified as factors associated with commitment and completion of change in lifestyle habits. These themes were: psychological beliefs, friends and family support, and transport and costs. 
The authors of the review conclude that these factors should be considered during consultations to promote a tailored approach to decision-making about the most suitable type of education and level of support [14].

The Health Belief Model (HBM), is a framework that is extensively used to explain changes and maintenance of health-related behaviours, and as a guiding model for health behaviour interventions [15]. HBM includes several key concepts and definitions: perceived susceptibility (one's belief regarding the risk of getting a condition); perceived severity (one's belief about how serious a condition and its sequelae are); perceived benefits (one's belief in the efficacy of the advised action to reduce the risk or seriousness of impact); perceived barriers (one's belief about the tangible and psychological costs of the advised action); self-efficacy (one's confidence in one's ability to take action) [15].

Although a concordance between patients and spouses regarding lifestyle habits exists, and patients report that changes in lifestyle habits depend on beliefs and family support, according to us, no study has qualitatively compared patients' and spouses' health beliefs about lifestyle habits after a cardiac event. Such data might be helpful in explaining lifestyle changes and their maintenance, and in designing future targeted interventions. The present study aimed to examine and qualitatively compare the health beliefs of patients with CHD and their spouses about lifestyle habits one year after the cardiac event.

\section{Methods}

\section{Design and method description}

This study was performed deductively and exploratively using directed qualitative content analysis according to Hsieh and Shannon's approach [16]. The analysis was guided by HBM as a framework in order to examine and describe the health beliefs of patients with CHD and their spouses about lifestyle habits, one year after the cardiac event, and furthermore to analyse and compare the beliefs. The advantage of this approach is the possibility of expanding on existing theory, e.g. HBM, which could benefit from further description or from being validated or extended conceptually [16, 17]. We set up four focus group interviews [18] with patients $(n=14)$ with CHD that had been verified about one year previously by myocardial infarction (MI) or by treatment 
with percutaneous coronary intervention and/or CABG. Subsequently, we conducted individual semi-structured interviews with the patients' spouses $(n=8)$ about one month after the focus group interviews with the patients.

\section{Setting and Participants}

We selected a purposeful sample of patients with CHD participating in the COR-PRIMstudy [19]. This study, hereafter called the main study, is an on-going, five-year prospective single - centre study randomised controlled study (NCT01462799), conducted in primary health care centres (PHC) $(n=6)$ in eastern Sweden. The aim of the main study is to discover whether problem-based learning (PBL) provided in PHC has long-term effects on empowerment and self-care after a cardiac event. The patients who were in the process of being enrolled in the main study were interviewed before being randomly allocated to patient education groups based on PBL or home-sent leaflets with patient information about CHD and lifestyle habits. The patients met the inclusion criteria of being: (1) a patient with CHD verified by MI and/or Percutaneous Coronary Intervention (PCI) and/or CABG within 12 months before the planned start of the intervention, (2) a patient who was stable regarding his/her cardiac condition and taking optimised cardiac medication that had not substantially changed during the previous month, (3) a patient who had completed heart school in hospital care; and was listed at one of six specific PHC centres. Exclusion criteria were: planned CABG or other conditions demanding continued cardiologist care; e.g. on-going contact with a heart failure clinic due to a need for drug titration or investigations, e.g. myocardial scintigraphy to detect ischemia before a new PCI; life expectancy $\leq$ one year; documented psychiatric disease causing difficulties cooperating with other people; or obvious abuse of alcohol or narcotics. Patients were also excluded if they were unable to communicate or read the Swedish language.

Recruitment of participants to the present qualitative study started simultaneously with the initial recruitment to the main study during September 2011. Patients were informed about the main study orally, and by written patient information, by three nurses working at an out-patient cardiac clinic in a hospital in south-east Sweden. They identified patients as eligible for the main study and gave the research team contact details for thirty-eight patients, of which 14 agreed to participate in four focus group 
interviews. The rational for the number of focus group interviews was based on that no new information emerged after that several health beliefs were discussed in three of four groups, in accordance with the literature [20]. The group size was based on that small groups give each participant more time to discuss his or her beliefs on the topics posed to the patients [18]. The focus group interviews ended with an enquiry about contacting their relatives to request their involvement in an interview study. The patients received a letter containing information aimed at the patient and the relative, with an invitation to the latter to participate in the present study. The relatives were defined by the patients according to the recommendations of Wright et al. who believe that the constitution of the family should be defined by the patient [21]. All patients who accepted the invitation chose their spouse to participate. The spouses, one man and seven women, were contacted by telephone and chose to participate, which was confirmed in writing in a reply letter to the researchers.

\section{Data collection}

The focus group interviews took place during September 2011. AKK, PT and SN, senior researchers not participating in the patients' care, interviewed the patients in PHC or at the university, locations considered neutral environments. The interviews lasted for approximately $1 \mathrm{~h} 45$ minutes, ranging from 75- 105 minutes. Self-reported patient characteristics and medical diagnoses were obtained via a self-constructed questionnaire and the hospital respectively, prior to the interviews (Table 1).

Insert Table 1 here

The main author AKK moderated all focus groups and PT or SN observed and took field notes. AKK and PT were nurses with PhDs, and SN was a general practitioner with a PhD. AKK and PT had long experience of interviewing patients in different projects. The spouses were individually interviewed by a medical student. The interviews (Table 2) were conducted in October 2011 and lasted for approximately 40 minutes, ranging from 25 - 45 minutes. The interviews took place mostly in the patients' homes, as chosen by the spouses. All individual interviews and focus groups were digitally recorded (Olympus digital voice recorder, DM-550) and transcribed verbatim. 
The focus group interviews were transcribed by a professional secretary working in a research unit at the university; the individual interviews were transcribed by the student. Insert Table 2 here

Data analysis and rigour

The analysis was performed according to the recommendations of Hsieh and Shannon [16]. We used directed content analysis to analyse the interview data of both the focus group interviews and the individual interviews. Firstly, the transcripts were checked for accuracy. Secondly, the analysis started with the first author AKK reading the transcripts as a whole to identify the meaning of the text. In this process of analysis the meaning of the text was found to be associated with health beliefs. Thirdly, all transcripts were read thoroughly word by word to highlight all text that on first impression seemed to represent health beliefs relevant to the aim. Fourthly, all highlighted passages were coded using the predetermined codes (Table 3). To ensure rigour and reliability during the analysis, in this step, PT collaborated with AKK by confirming or disconfirming the preliminary categorisations based on the patients' and spouses’ beliefs, which were assessed separately. Fifthly, all categorisations were compared between patients and spouses within each predetermined code. In this step, all the authors and a patient chosen from a national patient organisation for heart and lung patients acted as peer debriefers during a seminar in order to assess the first author's analysis of beliefs matching the HBM. During this assessment, discussion and considerations about categorisations were allowed.

Insert Table 3 here

\section{Ethical considerations}

The study was approved by the Regional Ethical Review Board in Linköping. Permission to conduct the study was obtained from the participating PHC. Informed consent was obtained from all patients and spouses after they had received information about the study. They were all informed that participation was voluntary and that refusal would not affect their care. They also were made aware that all data would be treated confidentially. 


\section{Findings}

An overview of the findings is presented below (Table 4 and 5). Insert Table 4 and 5 here

The Re-susceptibility, i.e. the patients' beliefs regarding the risk of having a new cardiac event, is described in the following. The patients believed that relapse after an MI was caused by physical exercise, which was considered as risky and dangerous. Causative risk factors e.g. smoking and heredity, could lead to CHD. They also believed that risk factors were harmless by considering relatives who were heavy smokers to have a healthy lifestyle.

The patients' beliefs also concerned security and control. Follow-up in health care was considered as providing security against deterioration. Unawareness about CHD was considered as causative by making them more susceptible to having the disease, as shown in this quotation.

“...I mean before I went in for my heart attack, I did not even know what blood pressure was, nothing, I had no idea about it and I had not bothered about it either” (focus group 3).

The spouses' beliefs within this category were that relapse of an MI was caused by overload/demands, which was considered to create physical and emotional stress. Causative risk factors for MI e.g. eating fatty food and smoking were considered. The spouses also believed artificial additives to be more causative of CHD compared to known risk factors, e.g. smoking or consumption of highly saturated fat, which did not always cause an MI, as shown in the following quotation.

"I come from Lapland and I mean where you eat these kinds of food with lots of fat, and drink the broth and stuff like that. I cannot with the best will in the world say it is low in fat so to speak, and he (grandfather) ate that all the time, and he lived until he was $95 . .$. usually it will be like a one-way debate somehow...that it is, either black or white, to eat fat... I believe perhaps it might also depend more, I think on the additives” (wife 5).

To sum up, the patients' beliefs within this category corresponded with the spouses' regarding relapse from overloading activities, risk factors, as well as factors presented as harmless. No spouse regarded security/control or unawareness of CHD as affecting the risk of having a new cardiac event.

The Benefits i.e. beliefs about the effect of the advice aimed at reducing the risk of CHD, are described in the following. The patients believed that individual focusing on 
stress reduction, anxiety relief, physical exercise, and healthy eating were beneficial and preventive habits to reduce the risk of CHD. Well-being was believed to come from new lifestyle habits e.g. stopping smoking, and physical exercise, as exemplified in this quotation.

A said "Yes it is really important to think of oneself ... if it becomes stressful... So only; I must think of myself more. Do as I think now, therefore, do not go into this now, but wait a while” B said: "It is about diet and exercise and all this. You have to (change) because the diet is very important for the blood fats and also for feeling well” (focus group 4).

The patients also pointed out that they felt safe through supervision. The conversation with the cardiac nurse brought greater safety into their lives, and furthermore, they believed that supervised physical exercise was advantageous for their rehabilitation.

"We do a lot of training, at around fourteen training stations. It is about both strength and endurance throughout. The advantages of it are that one is under surveillance, that they take your pulse and they take your blood pressure, and there is the benefit (of being supervised)" (focus group 3).

The spouses' beliefs were that preventive habits e.g. healthy eating promoted wellbeing, recovery and survival from CHD. Moreover, there were beliefs that health, wellbeing from new habits, and autonomy should be prioritised above money, and old habits.

"Health comes first, and it’s nice, I think when you have realised that, because money is not everything, your health is worth more...” (wife3).

Patients' and spouses' beliefs corresponded partly within this category regarding preventive habits and well-being from new habits. No spouse regarded supervision during physical exercise as something that could reduce the risk of CHD.

The Barriers i.e. beliefs about considerable psychological costs due to following the health care advice, are described in the following. The patients believed that the limiting body inhibited lifestyle habits, for example, due to difficulties in moving caused by a painful back or by dizziness. Unawareness of risk factors e.g. high blood pressure, and different family preferences concerning healthy eating inhibited changes in lifestyle habits.

The patients believed that a meaningless life without relatives, and old lifestyle habits were barriers to following advice. Depressive moods and changed personality were believed to hinder social life. Life lost meaning with a lack of family members, and the 
absence of physical exercise and smoking. Advice and reminders from health care personnel on smoking cessation were regarded as necessary but did not help when the patient did not want to quit. Moreover, the patients viewed barriers to medication in relation to the belief that the body was self-healing and controlled its own processes, as in the following quotations.

A said: "But it is divine when medicines drop away then disappear one after the other. It is wonderful so to speak... But one (the physician) must keep some kind of an eye on the patient to see how he or she is doing. So you can begin to pick away (the medication). I think we feel a lot better off, if it is removed, because the more your body can control its own processes, the better it is ...” and B said: " I have been struggling to cut down on the medicine and the doctors say "No, we will not take that risk", that I hear all the time” (focus group 1).

The spouses' believed that the limiting body inhibited lifestyle habits, for example, due to weight gain that overloaded the heart. Unawareness of e.g. what kind of food to cook, and different family preferences concerning lifestyle habits were pointed out as barriers, as shown in the following quotation.

"I have been told by my doctor that I must be active, so I go out and walk every morning before breakfast ... I try ... but then he (the patient) does not want to come along” (wife1).

Patients' and spouses' beliefs corresponded partly within this category regarding the limiting body, unawareness of risk factors, and family preferences in lifestyle habits. No spouse regarded a meaningless life or the belief that the body was self-healing as a considerable psychological cost due to following health care advice.

The Severity of CHD i.e. one's beliefs about the seriousness of a condition and its consequences, are described in the following. The patients believed that strenuous physical exercise should be avoided and that the future must be seized, meaning that life was regarded as important to use fully. Normalisation to life as usual was possible despite the cardiac event.

The spouses believed that strenuous physical exercise should be avoided. Anxiety and frailty were notified (due to the cardiac event); however, life was captured despite the anxiety, which did not take over one's life; normalisation to life as usual seemed possible regardless of the cardiac event, as shown in this quotation.

"He would not want to admit what he has been through, he wants to be as before ... that's the idea maybe, that it will be as before. He sometimes says: "I have to think about this sometimes" ... but it 
does not hang on him like a burden ... but the doctors have told him that he is going to live normally just like he did before, and he has kept that in mind. So I do not think we've changed so much more than ...no" (wife1).

Patients' and spouses' beliefs corresponded within this category. All considered that strenuous physical exercise should be avoided. They believed that life was important and should be captured/seized and that normalisation to life as usual was possible.

Self-efficacy i.e. the confidence in the patient's ability to take action, is described in the following. The patients, expressed beliefs about being targeted, strong-willed and strategic, as this male patient put it.

"I reckoned that I should be able to go to Uganda and watch the mountain gorillas and so on. But a prerequisite is that I, that I get strength and muscles and can go up into the mountains. But then you have to be "fighting fit", and that's the goal one might have then" (focus group 1).

Moreover, the patients concerned their confidence in following advice or failure to adhere to advice. Some patients believed that there was a need to meet people, and that socialising facilitated the feeling of being alive, as in this example.

"I am that kind of person, I always talk with anyone. I usually talk when I meet someone there in the woods. I usually stop and talk if someone wants. And there are a lot of people who want to talk there. I always meet people ... the same people. We can sit quite some time there in the woods ...And that means a lot as well, that I feel that I am alive and here” (focus group 2).

Actions in daily life such as go out for a fast walk/physical activity, stop smoking, and lose weight or recondition the house etc. were mentioned as individual activities.

The spouses' believed that adopting mutual approaches to changing lifestyle habits was a possible way to take action, as shown in these quotations.

"We are active and keep up ... trying to do it ... so you are not sitting and feeling depressed together. We hang out with people, we are like that...have always been” (wife7).

"We play boule twice a week, Thursday and Saturday. And he says, no not again. But once we get there its great fun. So it is only to nag, that works” (wife 2).

To sum up, patients' and spouses' confidence in the patient's ability to take action did not correspond. The spouses believed that adopting mutual approaches to changing lifestyle habits was a possible way to take action. Patients did not believe that their actions depended on collaboration with their spouses. However, some patients felt there was a 
need to meet people in general, and considered that socialising helped them feel that they were alive.

\section{Discussion}

The main findings of this deductively qualitative content analysis are that the patients' and the spouses' health beliefs about lifestyle habits differed in all main analytical categories of HBM except in perceived severity, where they were in agreement. The patients' beliefs comprised knowledge about CHD; health care controls and individualistic activities as meaningful to protect against CHD/relapse. A meaningless life and a self-healing body hindered compliance to healthcare advices. Thus, the patients relied more on their own capacity and the health care system, and without a pronounced belief that lifestyle habits should be performed in collaboration with their spouses. This differed totally from the spouses who instead claimed the importance of mutual collaboration to establish lifestyle habits. The spouses' beliefs comprised the value of considering different risk factors, eating habits and to collaborate around this to protect against CHD/relapse. Different preferences in the family and a limiting body hindered compliance to healthcare advices. An assumption is therefore that the spouses experienced problems with different preferences compared to the patients regarding changes in lifestyle habits.

Specifically, the patients' self-efficacy, i.e. their confidence in their own ability to take action towards a healthier living, was different to the spouses' beliefs. The patients emphasised the importance of being targeted, strong-willed and strategic to achieve a goal, and did not mention the spouse as involved. This regarded actions in daily life involving lifestyle habits and other projects such as reconditioning of the house etc. This is in line with another study showing that patients needed to focus more on themselves during recovery[22]. According to a study from Greece, patient's reactions are the result of an interpersonal relationship e.g. between the patient and the spouse, impacting on the patients' cognitive-emotional reactions, behaviour, and consequently their health [23]. Reactions might result in disagreements if the spouse's strategy is to perform mutual activities, and the patient's goal is to perform on their own. Therefore, the nurse and associated professionals need to develop ways to help patients and spouses to find strategies to handle lifestyle habits. The couple do not need to share the same opinion, but they need to know how to act when they disagree about certain behaviours. The finding 
regarding the patients' self-efficacy may also be explained by the fact that most spouses took on a participative role that involved attempts to take a practical part in changing lifestyle habits, communicating empathetically, and being positive about changes [10]. However, if the patient does not wish to collaborate, the spouse may need to further adjust his/her support according to the patient's needs and wishes.

Another important finding was that the patients' re-susceptibility, i.e. the belief regarding the risk of having a new cardiac event, corresponded between the patients and the spouses. The spouses' believed that relapse of an MI was caused by overload/demands, which was considered to create physical and emotional stress. This finding may be due to spousal anxiety, which is known from other studies of CABG, PCI and MI, which have revealed unmet needs among the spouses $[12,24]$. We also found that physical overload, heavy smoking and saturated fat were believed to be less likely to cause CHD compared to additives in groceries. These beliefs are challenging and may be explained by HBM, which is a value-expectancy theory that involves personal estimates of subjective hypotheses and expectations held by the subject. According to HBM, people need to feel threatened by their current behaviour and believe that change of a specific kind will result in a valued outcome at acceptable cost [15]. One could use the term 'episodic evidence', to explain the patients' beliefs. This term means that a person defends a behaviour, e.g. smoking, based on single events that demonstrate the opposite of the counsel given and expect it to be general [25]. In this category, only patients believed that access to follow-up and control could prevent the risk of CHD. Patients' desires for long-term monitoring and support from health care professionals have been identified elsewhere [26].

An interesting result concerned barriers to following medication regimens. The patients' views on taking medication involved a psychological cost-benefit analysis in which they viewed the body as self-healing and able to control its own processes without the influence of medication. Such beliefs display a general dislike of taking medicines, which is in accordance with other studies of patients with low medication adherence [27]. The belief that different preferences in the family inhibited lifestyle habits was a barrier that applied to both patients and spouses. This may be because patients' and spouses' expectations about desired changes may vary and cause arguments [22]. When such preferences differ, there is a risk that spouses who act collaboratively and try to support the patient's lifestyle habits will not succeed in their efforts. The behaviour of these spouses may be identified as demonstrating a regulative role i.e. trying to control the patient's 
lifestyle habits [10]. In addition, when spouses and patients have different beliefs about the patient's heart disease, less support is perceived by the patient. For, example, when patients believe that their disease is chronic and the spouse believes it to be temporary, this may give the patient a feeling of not being taken seriously [28].

The patients and spouses believed physical exercise to be important in order to reduce the risk of CHD. However, only the patients emphasised the importance of supervising this activity. Patients' and spouses' beliefs were in agreement regarding normalisation to normal life, which corresponded to the study of Astin et al. [29] who found that a transition process involved finding a new normality. However, another study revealed that spouses' beliefs and expectations and patients' efforts to regain normality in life did not match. The authors suggested that couples with such experiences may benefit from nurse counselling that highlights the possibilities of recognizing the spouse's otherness, and of appreciating the merits of both processes [22].

\section{Study limitations and strengths}

This study has several limitations. Data collection took different forms as focus group interviews and individual interviews were performed with the spouses and the patients respectively. At the same time, use of overlapping methods such as focus group interviews and individual interviews may improve the credibility [30]. Different interview guides were used and the interviews were conducted by different researchers. However, the data was collected within the context of the main study, COR-PRIM [19] focusing on beliefs about lifestyle habits, and the interview guides had that focus. To ensure trustworthiness, the data collection from focus group interviews and analysis of the whole body of data was performed by the first author (in charge of the main study) of the present study. The other authors supported the analysis as peer debriefers [31] by ensuring that the beliefs matched HBM, as identified by the first author. Examples of the analysis procedure are shown in table 3, which strengthens the trustworthiness of the study. There were 22 participants in total, which may be considered a small number. The spouses consisted mainly of women and there is reason to believe that the results would have been different with an opposite gender distribution. Despite these limitations, a strength of the study is that the participants lived together. This study has several other strengths. To our knowledge this is the first deductively qualitative content analysis focusing on beliefs held by couples after a cardiac 
event. Another strength is the focus on differences in beliefs between the patients and the spouses. Several studies have qualitatively investigated patients' and spouses' experiences, knowledge, attitudes and beliefs after a cardiac event [27]. However, no one has broadened the knowledge to include qualitative comparisons, as we did. Even though the interviews with the spouses were performed a month after the focus group interviews, a strength of this study is that this time frame was chosen to ensure that patients and spouses had gained experience of everyday life after the cardiac event, and had thereby developed health beliefs about lifestyle habits and the use of medication for CHD.

\section{Conclusion}

This study demonstrated that patients' and spouses' health beliefs differed in most predetermined main analytical categories of HBM. The patients relied more on their own capacity and the health care system while the spouses claimed the importance of mutual collaboration with the patient to establish lifestyle habits. The spouses therefore experienced problems with different family preferences compared to the patients regarding changes in lifestyle habits.

The patients' and spouses' beliefs should be followed-up, considered, acknowledged and discussed in primary health care by nurses and associated professionals. They should develop a tailored patient education e.g. problem-based group sessions that incorporates the patients' and spouses' beliefs as triggers for discussion and appraisal of the present lifestyle habits. This could facilitate possibilities to recognize and understand their different views and otherness leading to compromises and goals to work with.

Further research is needed to qualitatively explore and quantitatively determine what kind of interventions are the most effective in supporting and developing patients' and spouses' health beliefs and lifestyle habits after a cardiac event. 


\section{References}

1. Hilscher R, Bartley A, Zarski J. A heart does not beat alone: coronary heart disease through a family systems lens. Families, Systems \& Health. 2005;23(2):220-35.

2. Hong T, Gonzalez R, Franklin B, Franks M, Keteyian S, Artinian N. A dyadic investigation of exercise support between cardiac patients and their spouses. Health Psychology. 2005;24(4):430-4.

3. Jennings CS, Collier T, Mead A, Jones J, Holden A, Connolly S, et al. EUROACTION: do couples attending a hospital based multidisciplinary family cardiovascular prevention and rehabilitation programme share the same risk factors? Do they change together? European Journal of Cardiovascular Nursing 2008;1:S26-7.

4. Macken LC, Yates B, Blancher S. Concordance of riskfactors in female spouses of male patients with coronary heart disease. Journal of Cardiopulmonary Rehabilitation. 2000;20(6):361-8.

5. Thomson P, Niven C, Peck D, Howie K. Concordance between patients and partners before and after bypass grafting surgery. Journal of Cardiovascular Nursing. 2013;28(6):550-62.

6. Di Castelnouvo A, Quacquaruccio G, Donati M, de Gaetano G, Lacoviello L. Spousal concordance for major risk factors: A systematic review and metaanalysis. American journal of epidemiology. 2008;169(1):1-8.

7. Kotseva K, Wood D, De Backer G, De Bacquer D, Pyorala, K. Keil, U. EUROASPIRE III: a survey on the lifestyle, risk factors and use of cardioprotective drug therapies in coronary patients from 22 European countries. European Journal of Cardiovascular Prevention and Rehabilitation. 2009; 16(2):121-37.

8. Kotseva K, Wood D, De Backer G, De Bacquer D. Use and effects of cardiac rehabilitation in patients with coronary heart disease: results from the EUROASPIRE III survey. European journal of preventive cardiology. 2012;20(5):817-26.

9. Kotseva K, Wood D, De Bacquer D, De Backer G, Ryden L, Jennings C, et al. EUROASPIRE IV: A European Society of cardiology survey on the lifestyle, risk, factor and therapeutic management of coronary patients from 24 European countries. European journal of preventive cardiology. 2015;0(00):1-13.

10. Kärner A, Abrandt Dahlgren M, Bergdahl B. Rehabilitation after coronary heart disease:spouses' views of support. Journal of advanced nursing. 2004;46(2):20411.

11. Arefjord K, Hallaråker E, Havik OE, Maeland JG. Illness understanding, causal attributions and emotional reactions in wives of myocardial infarction patients. Psychology and Psychotherapy: Theory, Research and Practice. 2002;75:10114.

12. Moser D, Dracup K. Role of spousal anxiety and depression in patients' psychosocial recovery after a cardiac event. Psycosomatic medicine. 2004;66:527-32.

13. Lau-Walker M. Importance of illness beliefs and self-efficacy for patients with coronary heart disease. Journal of advanced nursing. 2007;60(2):187-98. 
14. Murray J, Craigs C, Hill K, Honey S, House A. A systematic review of patient reported factors associated with uptake and completion of cardiovascular lifestyle behavour change. BMC Cardiovascular Disorders. 2012;12(120). Janz N, Champion V, Strecher V. The Health Belief Model. In: Glanz K, Rimer B, FM. L, editors. Health Behavior and Health Education Theory, Research, and Practice. 3rd ed. San Francisco: Jossey-Bass; 2002. p. 45-63.

16. Hsieh H-F, Shannon SE. Three approaches to qualitative content analysis. Qualitative Health Research 2005;15:1277-88.

17. Mayring P. Qualitative content analysis. Forum: Qualitative social research. 2000;1(2):Art. 20.

18. Morgan D. Focus groups. Annual Review of Sociology. 1996;22:129-52.

19. Kärner A, Nilsson S, T. J, Andersson A, Wiréhn A-B, Wodlin P, et al. The effect of problem-based learning in patient education after an event of CORONARY heart disease - a randomised study in PRIMARY health care: design and methodology of the COR-PRIM study. BMC Family Practice. 2012;13(110):1-9.

20. Zeller, R.A. Combining qualitative and quantitative techniques to develop culturally sensitive measures. In: D.G. Ostrow and R.C. Kessler, editors. Methodological issues in AIDS behavioral research. Hingham MA, USA: Kluwer Academic Press;1993. p. 95-116.

21. Wright LM, Watson WL, Bell JM. Familjefokuserad omvårdnad Föreställningar i samband med ohälsa och sjukdom. Original title: Beliefs: the Heart of Healing in Families and Illness. Lund: Studentlitteratur; 2002.

22. Mahrer-Imhof, R., A. Hoffman, and E.S. Froelicher. Impact of cardiac disease on couples' relationships. Journal of advanced nursing. 2007;57(5):513-21.

23. Karademas, E. and I. Tsaousis. The relationship of patient and spouse personality to cardiac patients' health: Two observational studies of mediation and moderation. Annals of Behavioural Medicine. 2014; 47:79-91.

24. Carrol, D.L. Antecedents to the integration process for recovery in older patients and spouses after a cardiovascular procedure. International Journal of nursing practice. 2014;20:97-105.

25. Egidius H. Termlexikon i psykologi och psykiatri. (Term lexicon in psychology and psychiatry) Lund: Studentlitteratur; 2006.

26. Gregory S, Bostock Y, Backett-Milburn K. Recovering from a heart attack: a qualitative study into lay experiences and the struggle to make lifestyle changes. Family Practice. 2005;23:220-5.

27. Kelly M, McCarthy S, Sahm L. Knowledge, attitudes and beliefs of patients and carers regarding medication adherence: a review of qualitative literature. European journal of clinical pharmacology. 2014;70:1423-31.

28. Benyamini, Y., B. Medalion, and D. Garfinkel. Patient and spouse perceptions of the patient's heart disease and their associations with received and provided social support and undermining. Psychology and Health. 2007;22(7):765-85.

29. Astin F, Horrocks J, Closs J. Managing lifestyle change to reduce coronary risk: a synthesis of qualitative research on peoples experiences. BMC Cardiovascular Disorders. 2014;14(96).

30. Shenton A. Strategies for ensuring trustworthyness in qualitative research projects. Education for information. 2004;22:63-75.

31. Lincoln Y, Guba E. But is it rigorous? Trustworthyness and authenticity in naturalistic evaluation. In: Williams D, editor. Naturalistic evaluation- New directions for program evaluation. San Fransisco: Jossey-Bass; 1986. p. 73-84. 

Table 3. Example of the deductive qualitative analysis procedure of the transcripts, from codes to subcategories

\begin{tabular}{|c|c|c|c|}
\hline $\begin{array}{l}\text { Main analytical } \\
\text { HBM category }\end{array}$ & Transcripts about health beliefs & Codes & Subcategories \\
\hline \multirow[t]{2}{*}{ Benefits of advice } & $\begin{array}{l}\text { We have had season tickets (fitness club) ever since } \\
1992 \text { or something like that. And then we had our } \\
\text { children in '93 and ' } 95 \text {. Then there has been little to } \\
\text { and from depending on how much time you have had. } \\
\text { But we have continued the training. We use a } \\
\text { combination of fitness and strength training around } \\
\text { five days a week. I think that one has to believe in } \\
\text { something and I think I had the joy of it (the training) } \\
\text { when I had my heart attack that I managed as well as } \\
\text { I did (focus group1). }\end{array}$ & Regular exercise promotes recovery and survival & Preventive habits \\
\hline & $\begin{array}{l}\text { We are exercising a lot, and that is important, because } \\
\text { the training he has joined, he believes that it is really } \\
\text { good. He does not believe that he would have been so } \\
\text { well today if he not had attended this training ... it is } \\
\text { important to him, and he has certainly benefited from } \\
\text { it, I believe that (wife 4). }\end{array}$ & New exercise has positive effects on well-being post-MI & Well-being from new habits \\
\hline
\end{tabular}


Table 4. Beliefs concerning the risk of a new cardiac event, benefits of and barriers to receiving advice, severity of CHD and self-efficacy to take action identified among patients and spouses

\begin{tabular}{|c|c|c|}
\hline $\begin{array}{l}\text { Main analytical } \\
\text { HBM categories }\end{array}$ & $\begin{array}{l}\text { Examples of patients' } \\
\text { transcripts }\end{array}$ & $\begin{array}{l}\text { Examples of spouses' } \\
\text { transcripts }\end{array}$ \\
\hline $\begin{array}{l}\text { Re-susceptibility to a new } \\
\text { cardiac event }\end{array}$ & $\begin{array}{l}\text { “...I mean before I went in for my heart attack, I did } \\
\text { not even know what blood pressure was, nothing, I had } \\
\text { no idea about it and I had not bothered about it either” } \\
\text { (focus group 3). }\end{array}$ & $\begin{array}{l}\text { "I come from Lapland and I mean where you eat these } \\
\text { kinds of food with lots of fat, and drink the broth and } \\
\text { stuff like that. I cannot with the best will in the world } \\
\text { say it is low in fat so to speak, and he (grandfather) ate } \\
\text { that all the time, and he lived until he was 95...usually } \\
\text { it will be like a one-way debate somehow...that it is, } \\
\text { either black or white, to eat fat...I believe perhaps it } \\
\text { might also depend more, I think on the additives" (wife } \\
\text { 5). }\end{array}$ \\
\hline Benefits of advice & $\begin{array}{l}\text { A said "Yes it is really important to think of oneself ... } \\
\text { if it becomes stressful... So only; I must think of } \\
\text { myself more. Do as I think now, therefore, do not go } \\
\text { into this now, but wait a while" B said: "It is about diet } \\
\text { and exercise and all this. You have to (change) because } \\
\text { the diet is very important for the blood fats and also for } \\
\text { feeling well" (focus group 4). }\end{array}$ & $\begin{array}{l}\text { "Health comes first, and it’s nice, I think when you } \\
\text { have realised that, because money is not everything, } \\
\text { your health is worth more..." (wife3). }\end{array}$ \\
\hline
\end{tabular}


Table 4. Continues...

\begin{tabular}{|c|c|c|}
\hline $\begin{array}{l}\text { Main analytical } \\
\text { HBM categories }\end{array}$ & $\begin{array}{l}\text { Examples of patients' } \\
\text { transcripts }\end{array}$ & $\begin{array}{l}\text { Examples of spouses' } \\
\text { transcripts }\end{array}$ \\
\hline $\begin{array}{l}\text { Barriers due to following } \\
\text { advice }\end{array}$ & $\begin{array}{l}\text { A said: "But it is divine when medicines drop away } \\
\text { then disappear one after the other. It is wonderful so to } \\
\text { speak... But one (the physician) must keep some kind } \\
\text { of an eye on the patient to see how he or she is doing. } \\
\text { So you can begin to pick away (the medication). I } \\
\text { think we feel a lot better off, if it is removed, because } \\
\text { the more your body can control its own processes, the } \\
\text { better it is ...” and B said: "I have been struggling to } \\
\text { cut down on the medicine and the doctors say "No, we } \\
\text { will not take that risk", that I hear all the time" (focus } \\
\text { group 1). }\end{array}$ & $\begin{array}{l}\text { "I have been told by my doctor that I must be active, so } \\
\text { I go out and walk every morning before breakfast ... I } \\
\text { try ... but then he (the patient) does not want to come } \\
\text { along" (wife1). }\end{array}$ \\
\hline Severity of CHD & $\begin{array}{l}\text { A said: "You don’t think about your illnesses, you look } \\
\text { ahead and think about life....” and B said: "Yes, I } \\
\text { totally agree on that. I never think about it; it’s only the } \\
\text { medication in the morning” (focus group 6). }\end{array}$ & $\begin{array}{l}\text { "He would not want to admit what he has been } \\
\text { through, he wants to be as before ... that's the idea } \\
\text { maybe, that it will be as before. He sometimes says: "I } \\
\text { have to think about this sometimes" ... but it does not } \\
\text { hang on him like a burden ... but the doctors have told } \\
\text { him that he is going to live normally just like he did } \\
\text { before, and he has kept that in mind. So I do not think } \\
\text { we've changed so much more than ...no" (wife1). }\end{array}$ \\
\hline
\end{tabular}


Table 4. Continues...

\begin{tabular}{|c|c|c|}
\hline $\begin{array}{l}\text { Main analytical } \\
\text { HBM categories }\end{array}$ & $\begin{array}{l}\text { Examples of patients' } \\
\text { transcripts }\end{array}$ & $\begin{array}{l}\text { Examples of spouses' } \\
\text { transcripts }\end{array}$ \\
\hline Self-efficacy to take action & $\begin{array}{l}\text { "I reckoned that I should be able to go to Uganda and } \\
\text { watch the mountain gorillas and so on. But a } \\
\text { prerequisite is that I, that I get strength and muscles } \\
\text { and can go up into the mountains. But then you have to } \\
\text { be "fighting fit", and that's the goal one might have } \\
\text { then" (focus group 1). }\end{array}$ & $\begin{array}{l}\text { "We play boule twice a week, Thursday and Saturday. } \\
\text { And he says, no not again. But once we get there its } \\
\text { great fun. So it is only to nag, that works" (wife 2) }\end{array}$ \\
\hline
\end{tabular}


Table 5. Beliefs concerning the risk of a new cardiac event, benefits of and barriers to receiving advice, severity of CHD and self-efficacy to take action

\section{Beliefs identified among patients and spouses}

\begin{tabular}{|c|c|c|}
\hline $\begin{array}{l}\text { Main analytical } \\
\text { HBM category }\end{array}$ & $\begin{array}{l}\text { Patient } \\
\text { Subcategories }\end{array}$ & $\begin{array}{l}\text { Spouse } \\
\text { Subcategories }\end{array}$ \\
\hline $\begin{array}{l}\text { Re-susceptibility to a new } \\
\text { cardiac event }\end{array}$ & $\begin{array}{l}\text { Relapse caused by physical exercise } \\
\text { Causative risk factors } \\
\text { Harmless factors } \\
\text { Security and control } \\
\text { Causative unawareness }\end{array}$ & $\begin{array}{l}\text { Relapse caused by overload/demands } \\
\text { Causative risk factors/artificial additiv }\end{array}$ \\
\hline Benefits of advice & $\begin{array}{l}\text { Preventive habits } \\
\text { Well-being from new habits } \\
\text { Safe through supervision }\end{array}$ & $\begin{array}{l}\text { Preventive habits promoting well-bein } \\
\text { Well-being from new habits }\end{array}$ \\
\hline $\begin{array}{l}\text { Barriers due to following } \\
\text { advice }\end{array}$ & $\begin{array}{l}\text { Limiting body } \\
\text { Unawareness } \\
\text { Family preferences } \\
\text { Meaningless life } \\
\text { Self-healing body }\end{array}$ & $\begin{array}{l}\text { Limiting body } \\
\text { Unawareness } \\
\text { Family preferences }\end{array}$ \\
\hline Severity of CHD & $\begin{array}{l}\text { Avoiding strenuous physical exercise } \\
\text { Seized future } \\
\text { Normalisation }\end{array}$ & $\begin{array}{l}\text { Avoiding strenuous physical exercise } \\
\text { Capturing life despite anxiety } \\
\text { Normalisation }\end{array}$ \\
\hline $\begin{array}{l}\text { Self-efficacy to take } \\
\text { action }\end{array}$ & $\begin{array}{l}\text { Targeting and strong-willing } \\
\text { Following advice } \\
\text { Failing to adhere advice } \\
\text { Socialising and alive }\end{array}$ & Mutual approaches \\
\hline
\end{tabular}


